www.jmscr.igmpublication.org

Impact Factor 5.84

Index Copernicus Value: 83.27

ISSN (e)-2347-176x ISSN (p) 2455-0450

crossref DOI: _https://dx.doi.org/10.18535/jmscr/v5i4.208

Journal Of Medical Science And Clinical Research

\title{
Knowledge about Blood Donation among Undergraduate Students of GMC, Patiala, Punjab, India
}

\author{
Authors \\ Aradhna Sharma ${ }^{1}$, Kanchan Bhardwaj', Yasmeen Singh ${ }^{3}$ \\ ${ }^{1}$ Senior Resident, Department of Pathology, Government Medical College, Patiala \\ ${ }^{2}$ Prof \& Head, Deptt. Of Transfusion Medicine \& Immunohaematology, GMC, Patiala \\ ${ }^{3}$ Junior Resident, Department of Pathology, Government Medical College, Patiala \\ Corresponding Author \\ Dr Aradhna Sharma MBBS, MD (Pathology) \\ Senior Resident, Deptt of Pathology, Govt Medical Colledge, Patiala Punjab, India. \\ Email: aradhna1312@gmail.com
}

\begin{abstract}
Background: Students consists a large and healthy group who can meet the demand of safe blood. Knowledge studies have been used to understand the various factors that influence blood donation which is the basis for donor mobilization and retention strategies. However, there is paucity of studies on knowledge about blood donation among medical students.

Aim: To assess the level of awareness and knowledge regarding blood donation among the medical students for a safe and effective blood donor recruitment and retention programme.

Material and Methods: A cross sectional study was conducted among 341 medical students from Govt. Medical College, Patiala, Punjab, India using a predesigned questionnaire. A scoring mechanism was used to understand knowledge level. Data was analyzed in the form of percentage.

Results: The overall knowledge on blood donation was average. Majority (88.9\%) of students never donated blood. Knowledge level was found higher among old final students $(70.3 \%)$ and less among $2^{\text {nd }}$ year medical students (48.7\%). Most of the students (89.8\%) were aware about the suitable age group for blood donation and $72.5 \%$ stated that the minimum gap between donations should be 3 months. However only (25.5\%) knew about ideal weight required to donate blood. Only (60.4\%) were aware of common deferral conditions for blood donation.

Conclusion: The present study suggests that practice of blood donation can be enhanced by improving knowledge on blood donation among college students. The present study recommends that even medical student community needs to be educated about voluntary blood donation on regular basis as this will strengthen the recruitment and retention of blood donors to donate blood. There is this large pool of safe blood in college going students who are willing, but not tapped as source of blood donation.

Keywords: Knowledge, Medical students, Voluntary Blood donation.
\end{abstract}

\section{INTRODUCTION}

Blood can save millions of lives but many patients requiring transfusion do not have timely access to safe blood. A permanent shortage of blood is observed in blood services all over the world. ${ }^{[1,11]}$ The only source of blood is by blood 
donation. ${ }^{[2]}$ Selection of donors is an important mean to improve the overall safety of blood supply. ${ }^{[3]}$ It has been found that the voluntary, non-remunerated blood donation is the safest form of blood donation. ${ }^{[4]}$ However, the recruitment of voluntary, non-remunerated blood donors posed major challenges to transfusion services throughhout the whole world. ${ }^{[5,7]}$ As per World Health Organization (WHO) norms, $1 \%$ of population is generally the minimum needed to meet the country's most basic requirements for blood. ${ }^{[6]}$ Every year increase in population along with increase in life expectancy rate and associated increase in accidents and surgeries requiring blood, the rate of blood usage is on the rise.

Internationally, voluntary blood donation is considered as backbone of blood safety and safe transfusion practices. There is a serious need to improve the recruitment and retention of voluntary donor population to ensure a sustainable and safe blood transfusion practice. According to WHO, an estimated $38 \%$ of reported VBDs are contributed by people under the age of $25 \mathrm{yrs}$. WHO also insist countries to focus on young people to achieve $100 \%$ regular, voluntary, nonremunerated blood donation by the year 2020. ${ }^{[8]}$ Even when they are too young to donate, they can be educated to become voluntary donors when they reach the legally accepted age group. ${ }^{[9]}$ All countries in South East Asian Region are trying to eliminate culture of replacement donation and moving towards $100 \%$ voluntary blood donation. $^{[10]}$

According to World Health Organization (WHO), young people should be the special target group because they form a great part of the population and are generally full of zeal and enthusiasm.

Young students are healthy, active, dynamic, receptive and constitute a greater proportion in the Indian population. Lack of information and knowledge is the principal factor discouraging non-donors from donating blood. ${ }^{[1]}$ Thus, young students need to be educated, inspired and motivated to donate blood voluntarily on regular basis.

\section{MATERIAL AND METHODS}

This study was conducted among $2^{\text {nd }}$ and final year medical undergraduate students in Government Medical College, Patiala, Punjab, India. Three hundred and forty one students (190 students of final year and 151 of $2^{\text {nd }}$ year) participated in this study. A briefing was given to the participants about the aim of this study and assured confidentiality in the collection of personal data. A well-structured and pretested questionnaire on knowledge and practice on blood donation was assessed among students. A scoring mechanism was used to understand knowledge level and practice on blood donation; each correct answer was given one score and results were expressed in percentage. Data collected was analyzed using SPSS version 21.

\section{RESULTS}

In the present study, overall knowledge (Table 1) on blood donation among respondents was 59.5 $\%$. Overall final year students showed significantly higher knowledge $(70.3 \%)$, compared to $2^{\text {nd }}$ year students $(48.7 \%)$. Most of the students $(\mathrm{n}=300)$ knew suitable age group (18-65 yrs)for blood donation but surprisingly many (74.5\%) were not aware of minimum weight requirement for blood donation.

In our study, $70.5 \%$ students had the correct knowledge regarding minimum interval of blood donation. But only $42.5 \%$ of the students were aware about the number of lives that can be benefited from one unit of whole blood. About $(88.9 \%)$ of the students were non-donors, of which, most were from $2^{\text {nd }}$ year. In our study, only $51.3 \%$ of students knew about common temporary deferral conditions in women and nearly $60 \%$ were aware of permanent deferral conditions. None of the participant was able to respond to the questionaaire with $100 \%$ accuracy.

There was statistically significant correlation between level of knowledge and practice of blood donation (Table 1). 
Table 1: Knowledge and practice on blood donation

\begin{tabular}{|c|c|c|c|}
\hline $\begin{array}{l}\text { Knowledge }(\text { No of Students=341) } \\
\text { Final year- } 190 \text { students } \\
2^{\text {nd }} \text { year------151 students }\end{array}$ & Final year(\%) & $2^{\text {nd }}$ year $(\%)$ & Average(\%) \\
\hline Suitable age for blood donation & 93.6 & 86.0 & 89.8 \\
\hline Minimum weight for blood donation & 35.7 & 15.2 & 25.5 \\
\hline Minimum haemoglobin to donate blood & 89.4 & 55.6 & 72.5 \\
\hline $\begin{array}{l}\text { No of times a healthy male and female can donate } \\
\text { blood in a year }\end{array}$ & 82.1 & 58.9 & 70.5 \\
\hline Separation of components from whole blood & 74.6 & 52.8 & 63.7 \\
\hline $\begin{array}{l}\text { Number of lives saved from each unit of donated } \\
\text { blood }\end{array}$ & 56.6 & 28.4 & 42.5 \\
\hline Temporary deferral conditions in females & 53.6 & 49 & 51.3 \\
\hline $\begin{array}{llll}\begin{array}{l}\text { Permanent deferral conditions like hepatitis B, } \\
\text { hepatitis C, epilepsy }\end{array} & & & \\
\end{array}$ & 76.8 & 44 & 60.4 \\
\hline \multicolumn{4}{|l|}{ Practice } \\
\hline I donated blood & 15.7 & 6.6 & 11.1 \\
\hline
\end{tabular}

\section{DISCUSSION}

Even after combined efforts from the Government and International Agencies such as Red Cross Society and World Health Organization, the supply of safe blood is still in short of global demand. ${ }^{[12]}$ This study was conducted in order to obtain information about knowledge among students of medical college regarding blood donation and deferral conditions.

A total of 341 students responded to the questionnaire. All the respondents were eligible for blood donation as they were in the acceptable age group, All the participants were questioned to assess their knowledge about various aspects of blood donation and blood transfusion.

Knowledge on blood donation among students was measured using the following questions, the general requirements to become an eligible donor, right age and ideal weight for blood donation, how many times a year a healthy male and female can donate blood, components of donated blood, the maximum number of lives saved from one unit of donated blood and also common conditions of temporary and permanent deferral.

In the present study, overall knowledge (Table 1) on blood donation among respondents was 59.5 $\%$. Final year students showed significantly higher knowledge $(70.3 \%)$, compared to $2^{\text {nd }}$ year students (48.7\%). Most of the students (89.8) knew suitable age group (18-65 yrs)for blood donation but surprisingly, many were $(74.5 \%)$ not aware of minimum weight requirement for blood donation. In contrast, a study conducted in Saudi Arabia on 500 students revealed that only $0.06 \%$ were aware of suitable age for blood donation, while $28 \%$ knew about the necessary weight. ${ }^{[13]}$ Similarly, majority $92 \%$ of the students were aware of suitable age for blood donation in a study done by Giri and Phalke. ${ }^{[14]}$

Approximately $72 \%$ of the respondents had knowledge about minimum heamoglobin levels required for blood donation. In our study, $70.5 \%$ students had the correct knowledge regarding minimum interval of blood donation which was somewhat similar with the study of Agarvat Amit et $\mathrm{al}^{[17]}(80 \%)$. In a similar study, Chopra et al ${ }^{[18]}$ and Aslami et $\mathrm{al}^{[19]}$ found that their subjects who had correct knowledge about minimum interval of blood donation was $48.9 \%$ and $45 \%$ respectively. In the present study, it was found that only $42.5 \%$ of the students were aware about the number of patients that can be benefited from one unit of whole blood. This was in contrast to the studies done by Devi et al ${ }^{[20]}(63.9 \%)$ and Aslami et al ${ }^{[19]}$ $(64 \%)$. Manikandan et $\mathrm{al}^{[15]}$ found in his study that only $22 \%$ of the students were aware about the number of patients that can be benefitted from one unit of blood. This result strongly recommends that frequent awareness should be given to the students on blood components i.e, separation of one unit of blood can save up to 4 lives. ${ }^{[21]}$ 
The study showed that most of participants (88.9\%) had never donated blood so far, which is almost comparable with studies among health professional students by Manikandan et $\mathrm{al}^{[15]}$ (89.25\%), Sunetra Sarma et $\mathrm{al}^{[24]}(92 \%)$, and Desai et al ${ }^{[16]}(78.7 \%)$. But it was different among students in studies conducted by Kowsalya et al ${ }^{[26]}$ $(62.6 \%)$, Giri et $\mathrm{al}^{[14]}(52.5 \%)$, and Nwogen et $\mathrm{al}^{[27]}(22 \%)$. Because of background of knowledge, medical students generally have positive attitude towards voluntary blood donation and they may be easily motivated towards blood donation.

In our study, knowledge regarding blood donation was higher in final year students and higher number of blood donors in final year indicate there is positive association among knowledge and practice on blood donation which suggests that positive attitude and practice can be improved by inculcating knowledge on blood donation among medical students. This will help to achieve target of $100 \%$ voluntary blood donation. This study suggests that lessons about blood donation should be incorporated in the initial stages of higher education and periodic awareness program should be there for recruitment and retention of donors. This is in contrast to reports by Anwer et $\mathrm{al}^{[23]}$ and Hosain et $\mathrm{al}^{[22]}$, in which they discussed that greater knowledge does not lead to blood donation.

Bani and Giussani ${ }^{[28]}$ reported that higher rate of deferrals in women are responsible for low proportion of female donors. The present study strongly suggests that deferrals should be counseled that most of these deferrals are temporary and can become healthy donors in the subsequent blood donations.

Thus analyzing all the observations from the study, it is evident that knowledge about blood donation is average among medical students and knowledge has positive association with practice of blood donation. Our study validates the need for regular awareness programmes and introduction of course about safe blood practices and voluntary donation at early stage in medical colleges. Medical students know the importance and need of deferrals so they can self exclude themselves in situations when they are not fit to donate. This will ensure safe donor selection, as directed donors may hide their occult illness history $^{[29,30]}$ and hence compromising the safety of blood. In addition, medical students can be a source of guidance to their friends, family and general public and can motivate them about voluntary blood donation.

\section{CONCLUSION}

Awareness sessions on voluntary blood donation should be held regularly among college students to improve practice of blood donation and to remove misconceptions about voluntary blood donation.

\section{REFERNCES}

1. Sojka BN. The blood donation experience: perceived physical, psychological and social impact of blood donation on the donor. Vox Sang 2003;84:120-128.

2. Olaiya MA, Ajala A, Olatunji RO. Knowledge, attitudes, beliefs and motivation towards blood donation among blood donors in Lagos, Nigeria. Transfusion Medicine2004;14:13-17.

3. Van den Burg PJ, Vrielink H, Reesink HW. Donor selection: The exclusion of high risk donors? Vox Sang 1998;74Suppl 2: 499-502.

4. Leilola J. Non-remunerated donations. DevBiol Stud 1993; 81: 51-56.

5. Misje AH, Bosnes V, Heiser HE. Gender differences in presentation rates, deferrals and return behavior among Norwegian blood donors. Vox Sang 2010;98:241-248.

6. World Health Organization. Blood Transfusion Safety.2008. Availalble from: http://www.who.int/bloodsafety/voluntary donation/en/

7. Zaller N, Nelson KE, Ness P, Wen G, Bai $X$, Shah H. Knowledge, attitude and practice survey regarding blood donation 
in a Northwestern Chinese City. Transfus Med 2005; 15: 277-286.

8. World Health Organization-International Federation of Red Cross and Red Crescent Societies.

Availableat:http://www.who.int/bloodsafet y/publications/9789241599696-eng.pdf.

9. Blood Safety and Donation: Fact Sheet No. 279. June 2008, Available at:http://www.who.int/mediacentre/factshe ets/fs279/en/.

10. Bharucha ZS. Donor management in South East Asian Region (SEAR). DevBiol (Basel). 2005; 120: 145-153.

11. Fernandez Montoya A, de Dios Luna del Castillo J, Lopez Berrio A, Rodriguez Fernandez A. Attitudes, beliefs, and motivations in blood donors and nondonars. Sanre (Barc) 1996;41:427-440.

12. Damesyn MA, Glynn SA, Schreiber GB, Ownby HE, Bethel J, Fridey $\mathrm{J}$ et al. Behavioral and infectious disease risks in young blood donors: Implications for recruitment. Transfusion 2003; 43: 15961603.

13. Alam M, Masameh B. Knowledge, attitudes and practices regarding blood donation among the Saudi population. Saudi Med J 2004; 25:318-321.

14. Giri PA, Phalke DB. Knowledge and Attitude about Blood Donation Amongst Undergraduate Students of Pravara Institute of Medical Sciences Deemed University of Central India. Ann Trop Med Public Health 2012;5: 569-573.

15. Manikandan S, Srikumar R, Ruvanthika PN; A study on knowledge, attitude and practice on blood donation among health Professional students in Chennai, Tamil Nadu, South India. Int J Sci Res Pub 2013; 3 (3): 1-4.

16. Desai KN, Satapara V. A Study on Knowledge, attitude, and practice on blood donation among health professional students in Anand: Gujarat. J Appl Haematol 2014; 5: 51-53.

17. Agarvat Amit H, GhariaAmit A, Dhruva Gauravi, Mahesh Kakadia. Knowledge, Attitude, and practice of voluntary blood donation among medical students of PDU Medical College, Rajkot. Int J Curr Res 2014;6(5):6939-6941.

18. Chopra D, Jauhari N. Knowledge, attitude and practice towards voluntary blood donation among medical students in Barabanki District, India. Indian J Community Health 2015; 27(3).

19. Ahmed NadeemAslami, Abraham Jobby, Sony Simon, NahlaNazarudeen, Pranav Raj, MohamammedRamees at al. Assessment of Knowledge, Attitude and Practice (KAP) of blood donation among Medical students of a Medical College in Kollam, Kerala. J Evol Med Dent Sci 2015;4(35):6086-6095.

20. Devi HS, Laishram J, Shantibala K, Elanbam V. Knowledge, Attitude and practice (KAP) of blood safety and donation. Indian Med Gazette 2012;1:1-5.

21. Stacy A, and Gurevitz MD. Update and utilization of component therapy in blood transfusion 2011;42: 235-240.

22. Hosain GM, Anisuzzaman M, Begum A. Knowledge and Attitude towards voluntary blood donation among Dhaka University students in Bangladesh. East Afr Med J 1997;74:549-553.

23. Anwer MO, UI Fawwad SH, Anwer S, Ali A. Attitude towards blood donation among medical and non-medical students across Karachi. Asian J TransfusSci 2016; 10: 113-117.

24. SunetraSarma, Suresh Roy. Awareness about Blood Donation among Medical Students in Manipur. Sch. J. App. Med. Sci.,2016;4(3E): 994-996.

25. Wiwanitkit V. Knowledge about blood donation among a sample of Thai 
University students. Vox Sang2002;83: 97-99.

26. Kowsalya V, Vijayakumar R, Chidambaram R, Srikumar R et al. A study on Knowledge, Attitude and Practice Regarding Voluntary Blood Donation among Medical Students in Puducherry, India. Pakistan Journal of Biological Sciences 2013;16(9): 439-442.

27. Nwogoh B, Aigberadion U, Nwannadi AI.Knowledge, attitude, and practice of voluntary blood donation among health workers at the University of Benin teaching Hospital, Benin City, Nigeria. J Blood Transfusion 2013. PMID: 24222890 [PubMed] PMCID: PMC3810036.

28. Bani M, Giussani B. Gender differences in giving blood: A review of the literature. Blood Transfus 2010;8: 278-287.

29. Pink J, Thomson A, Wylle B. Infectious disease markers in autologous and directed donations. Transfus Med 1995; 4: 135138.

30. US Department of Health and Human Services. 2009 National blood collection and utilization survey report. Washington, DC: DHHS, 2011(in press). 